\title{
The Differential Immunomodulating Effects of Levan and DFA-IV on Macrophage Function
}

\author{
Sulkyoung Park ${ }^{1}$ Ki-Hyo Jang ${ }^{2}$, Mi-Hyun Kim ${ }^{2}$, Jung Dae Lim ${ }^{1}$, Eun Tek Han ${ }^{3}$, \\ Seon-A Jang ${ }^{1}$, Kyungho Kim ${ }^{4}$, Suhkneung Pyo ${ }^{4}$, and Eun-Hwa Sohn $^{1 \dagger}$ \\ ${ }^{1}$ Department of Herbal Medicine Resource and ${ }^{2}$ Department of Food and Nutrition, \\ Kangwon National University, Gangwon 245-711, Korea \\ ${ }^{3}$ Department of Parasitology, College of Medicine, Kangwon National University, Gangwon 200-701, Korea \\ ${ }^{4}$ College of Pharmacy, Sungkyunkwan University, Gyeonggi 440-746, Korea
}

\begin{abstract}
Di-D-fructose-2,6':6,2'-dianhydride (DFA-IV) is a disaccharide consisting of two fructose residues that are prepared from levan by levan fructotransferase. Levan is a homopolysaccharide composed of D-fructofuranosyl residues joined by $\beta-(2,6)$ and $\beta-(2,1)$ linkages. We compared the immunomodulatory effects of levan with DFA-IV. Tumoricidal activity, phagocytosis and nitric oxide (NO) production were examined in levan- and DFA-IV-treated RAW264.7 cells. The NO production, tumoricidal and phagocytic activities were significantly increased in both treated cells. The results indicate that levan has significantly greater effects on tumoricidal activity than DFA-IV at low concentrations $(1 \mu \mathrm{g} / \mathrm{mL})$ and its effect on NO production shows a similar pattem. These results suggest that tumoricidal activity induced by both samples is mediated by NO production.
\end{abstract}

Key words: di- $\beta$-D-fructofuranose dianhydride IV, DFA-IV, levan, macrophage, immunomodulation

\section{INTRODUCTION}

Levans are natural homopolysaccharides composed of D-fructofuranosyl residues joined by $\beta-(2,6)$ and $\beta-(2,1)$ linkages. Low-molecular-weight $(2 \mathrm{kDa} \sim 60 \mathrm{MDa})$ levans are produced in plants as carbohydrate reserves (1). Their molecular structure is a short linear chain of $\beta-(2 \rightarrow$ 6)-fructose. In microorganisms, levans have higher molecular weights and generally extensive branching through $\beta-(2 \rightarrow 1)$ linkages are present in addition to the $\beta-(2 \rightarrow 6)$ linkages seen in levans of plants. Di-D-fructose-2,6': 6,2'-dianhydride (DFA-IV) is a disaccharide consisting of two fructose residues which can be synthesized chemically or enzymatically from fructans, inulin and levanall naturally occurring fructose homopolysaccharides $(1,2)$. Five kinds of difructose dianhydrides (DFA I-V) have been found. DFA II and V can be synthesized only by chemical processes, while the others can be produced enzymatically (2). DFA-I and III are produced from inulin by the action of inulin fructotransferase and DFA-IV is produced from levan by the action of levan fructotransferase (LFTase). However, production of microbial levan and DFA-IV is problematic because the purification from the culture broth is difficult due to its high viscosity and the use of large amounts of organic solvent (3). Recently, it has been reported that DFA-IV could be produced from levan by the reaction of LFTase from Arthrobacter oxydans J17-21 by means of LFTase gene cloning from A. ureafaciens K2032 (4-6). It has been reported that levan strongly induces IL-12 and TNF- $\alpha$ in macrophages (7). Although DFA-IV is a derivative of levan, published scientific information regarding its immunomodulation activity is scarce.

Macrophages have been shown to be an important component of host defense against bacterial infection and cancer $(8,9)$. Large pools of macrophages, thought to be of mononuclear phagocyte origin, are located throughout the body and historically have been identified by different names according to their location in the body, including peritoneum (peritoneal macrophages), brain (microglia), bone (osteoclast) and liver (Kupffer cells). This host wide system of macrophages undergoes developmental changes in response to various signals in which they acquire or increase some functions and lose or decrease others. Four general stages of activation have been defined and cells in these stages are called resident, inflammatory (or responsive), primed and fully activated macrophages $(10,11)$ in the murine system. When exposed in vitro IFN- $\gamma$ and LPS, inflammatory macrophages can develop the capacity to kill tumor cells, and these stages are called fully activated macrophages.

${ }^{\dagger}$ Corresponding author. E-mail: ehson@kangwon.ac.kr

Phone: +82-33-570-6492, Fax: +82-33-570-6499 
During sequential development through the various stages, macrophages increase in phagocytic activity and release various materials such as cytokines and reactive intermediates and then carry out nonspecific immune responses $(10,12)$. Especially, there has been great interest in the reactive nitrogen intermediate, nitric oxide (NO) which is considered to be a central molecule in the regulation of the immune response to tumors because of its cytotoxic effects (13-15). It is known that inducible nitric oxide synthase (iNOS) is expressed in many different cell types and increased iNOS enzymes produces high levels of NO $(14,15)$. In the present study, we investigated the comparative immunomodulatory effects of DFA-IV and levan on tumoricidal and phagocytic activities of macrophages.

\section{MATERIALS AND METHODS}

\section{Preparation of levan and DFA-IV}

Bacterial levan (MW $\left.6 \times 10^{6} \mathrm{Da}\right)$ from Zymomonas mobilis was prepared as described previously (16) and obtained from RealBioTech Co. Ltd. (Daejon, Korea). DFA-IV was synthesized from levan using LFTase as described previously (4) and obtained from RealBioTech Co. Ltd., respectively.

\section{Cell culture}

RAW264.7 (mouse leukaemic monocyte macrophage cell line) and B16 (murine melanoma cell line) were obtained from ATCC (Manassas, VA). The cells were maintained in RPMI 1640 medium (Cambrex, Walkersville, MD) supplemented with $10 \%$ fetal bovine serum (Cambrex) and 2\% Penicillin/streptomycin (Cambrex) and incubated at $37^{\circ} \mathrm{C}$ in $5 \% \mathrm{CO}_{2}$.

\section{MTT assay for cell viability}

Cell viability was determined by the 3-(4,5-dimethylthiazol-2-yl)-2,5-diphenyltetrazolium bromide (MTT) assay as described previously (17). Briefly, the cells were seeded in 96-well plates at density of $5 \times 10^{4}$ cells per well and incubated with various concentrations of two samples for $24 \mathrm{~h}$. The cells were washed once with D-PBS and $200 \mu \mathrm{L}$ of MTT solution $(25 \mu \mathrm{g} / \mathrm{mL}$ in media) was added to each well. After incubation at $37^{\circ} \mathrm{C}$ under $5 \% \mathrm{CO}_{2}$ for $4 \mathrm{~h}$, the MTT solution was carefully discarded and the formazan blue crystals formed by the reduction of MTT was dissolved in $150 \mu \mathrm{L}$ DMSO. The amount of formazan was determined by absorbance at $540 \mathrm{~nm}$ using a microplate reader (Menlo Park, CA).

\section{NBT assay for phagocytosis}

Phagocytosis was measured by nitro blue tetrazolium (NBT) reduction assay as described previously (18). The cells were seeded in 96-well plates at a density $5 \times 10^{4}$ cells per well and incubated with various concentrations of two samples for $24 \mathrm{~h}$. The cultured media was then removed, and $50 \mu \mathrm{L}$ of zymosan $\left(5 \times 10^{6}\right.$ particles $\left./ \mathrm{ml}\right)$ and $0.6 \mathrm{mg} / \mathrm{mL}$ NBT were added to each well. After an additional incubation for $1 \mathrm{~h}$, the cells were washed twice with cold D-PBS and the optical density of reduction product of NBT (a purple insoluble formazan) was determined at $540 \mathrm{~nm}$ using a microplate reader.

\section{Nitrite determination}

The cells were treated with various concentrations of two samples for $24 \mathrm{~h}$ and the accumulation of nitrite in culture supernatants was measured as described by Ding et al. (19). $100 \mu \mathrm{L}$ aliquots of culture supernatants were mixed with an equal volume of Griess reagent (mixture at 1:1 of naphthylethylenediamine dihydrochloride and $1 \%$ sulphanilamide in $5 \% \mathrm{H}_{3} \mathrm{PO}_{4}$ ) and incubated at room temperature for $10 \mathrm{~min}$. Nitrite concentration was calculated from a $\mathrm{NaNO}_{2}$ standard curve.

\section{Macrophage-mediated tumoricidal activity}

The assay for macrophage tumoricidal activity was based on an assay described elsewhere (17). Briefly, macrophages $\left(1 \times 10^{5}\right.$ cells/well) were first incubated in either medium alone or in medium supplemented with various doses of the two samples for $24 \mathrm{~h}$ in 96-well plates. Macrophages were then washed with RPMI-FBS to remove the two samples and then co-incubated with B16 melanoma cells $\left(1 \times 10^{4}\right.$ cells/well; effector : target cell ratio of 10:1) for $24 \mathrm{~h}$. The enzyme activity of viable cells was measured by addition of MTT to each well. After additional incubation for $4 \mathrm{~h}$, the amount of formazan was determined by absorbance at $540 \mathrm{~nm}$ using a microplate reader (Menlo Park, CA, USA). Cytotoxic activity is expressed as the percentage of tumor cytotoxicity by the following formula: $[1-\{\mathrm{OD}$ of (target cells + macrophages) $-\mathrm{OD}$ of macrophages $\} / \mathrm{OD}$ of target cells] $\times 100$.

OD of target cells is the optical density of B16 melanoma cells and OD of macrophages is the optical density of macrophages.

\section{Westem blot analysis}

The amount of iNOS was measured by Western blot analysis. After $6 \mathrm{~h}$ of incubation with or without two samples, cells in six-well plates were lysed in sodium dodecylsulfate polyacrylamide gel electrophoresis buffer. Protein concentrations were measured using the DC Protein Assay (Bio-Rad Laboratories, Hercules, CA, USA). Twenty micrograms of each sample was electrophoresed on $10 \%$ sodium dodecylsulfate polyacrylamide gel electrophoresis gels and transferred to Hybond-ECL 
nitrocellulose membranes (Amersham Biosciences, Piscataway, NJ, USA). The membranes were blocked with 5\% skim milk in Tris-buffered saline/non-fat Tween for $1 \mathrm{~h}$. The membranes were incubated with primary antibody against iNOS for $24 \mathrm{~h}$. They were then washed with Tris-buffered saline/non-fat Tween once for $15 \mathrm{~min}$ and three times for 5 min and incubated with secondary ALP-conjugated anti-rabbit antibody for $1 \mathrm{~h}$. The membranes were washed again as described above. Autoradiography was carried out using an enhanced chemiluminescence kit (Amersham Bioscience).

\section{Statistical analysis}

The data is expressed as mean \pm SE The statistical difference between the groups was determined using a one-way analysis of variance (ANOVA) with a Dunnett's t-test. A p value $<0.05$ was considered significant.

\section{RESULTS AND DISCUSSIONS}

\section{Effects of levan and DFA-IV on cell viability}

To determine the optimal concentrations of DFA-IV and levan for stimulating macrophages, we evaluated the proliferative effect of DFA-IV and levan on the cell viability of RAW264.7. As shown in Fig. 1, DFA-IV and levan had no effect on cell viability. In addition, when the cells were treated with DFA-IV at $500 \mu \mathrm{g} / \mathrm{mL}$ for $24 \mathrm{~h}$, cell cytotoxicity appeared (data not shown). Therefore, in all subsequent experiments DFA-IV and levan were used at 1 to $100 \mu \mathrm{g} / \mathrm{mL}$ for $24 \mathrm{~h}$.

\section{Effects of levan and DFA-IV on phagocytosis}

Phagocytosis is the primary function of macrophages, which leads to enhance a diverse range of antimicrobial and cytotoxic responses including generation of respiratory bust, secretion of inflammatory mediators and antigen presentation. In this study, we examined the effects of DFA-IV and levan on phagocytosis of macrophages. When RAW264.7 cells were treated with various concentrations of DFA-IV or levan in the same concentration range $(1 \sim 100 \mu \mathrm{g} / \mathrm{mL})$ for $24 \mathrm{~h}$, phagocytic activity was significantly increased (Fig. 2). However, levan had no effects on phagocytic activity of macrophages at low concentrations $(1 \mu \mathrm{g} / \mathrm{mL})$. These results suggest that the two samples have different effects on phagocytosis of marophages depending on concentrations.

Effects of levan and DFA-IV on macrophage tumoricidal activity

To examine whether levan or DFA-IV treatment stimulates the tumoricidal activities of macrophages against target tumor cells, macrophages were co-cultured with B16 cells for $24 \mathrm{~h}$. B16 tumor cells were used as the
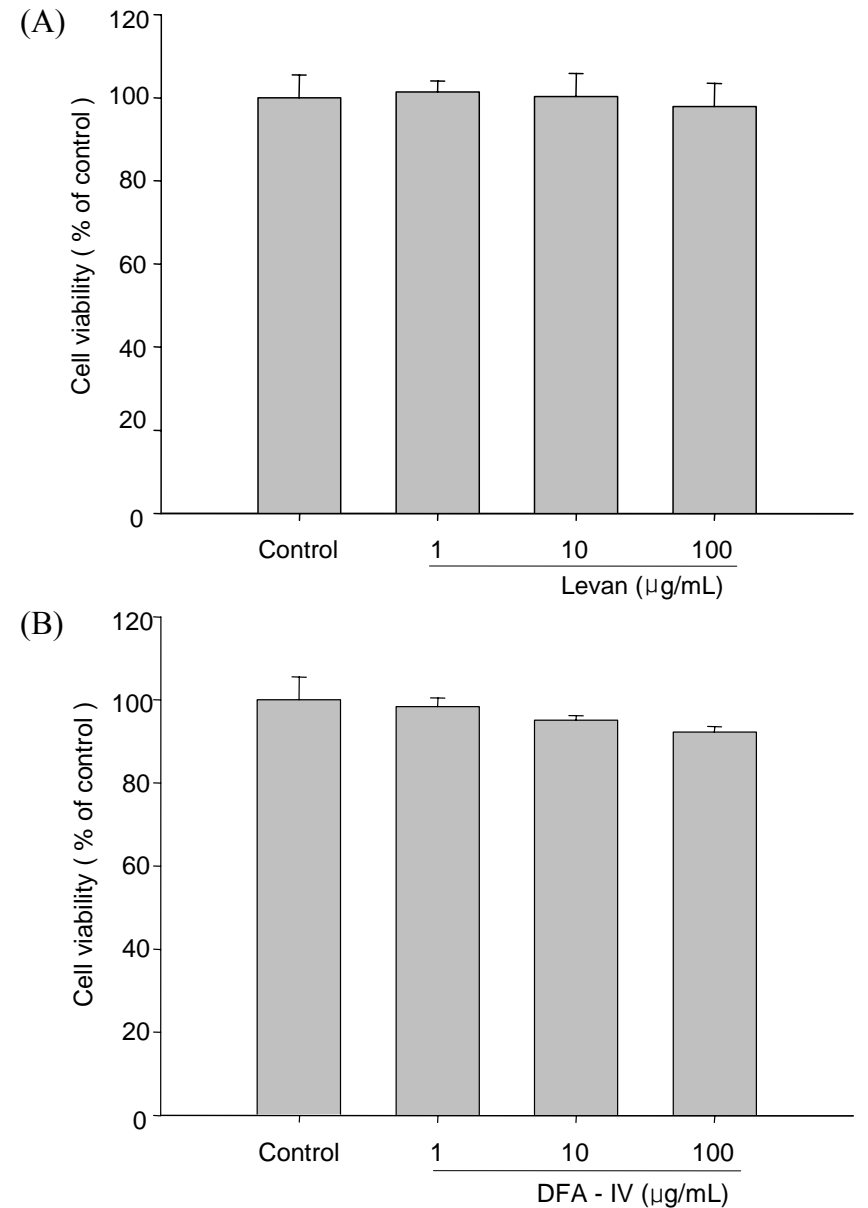

Fig. 1. Effects of levan and DFA-IV on cell viability. RAW264.7 cells $\left(1 \times 10^{5}\right.$ cells/well $)$ were treated with various doses of levan and DFA-IV for $24 \mathrm{~h}$, respectively. The cell viability was determined using the MTT assay and was expressed as a percentage of the untreated control. The data represents the mean $\pm \mathrm{SE}$ of quadruplicate experiments.

target since they are either TNF- $\alpha$ or NO sensitive. As shown in Fig. 3, both levan and DFA-IV enhanced the tumoricidal activity of macrophages. However, levan had maximal effects on tumoricidal activity of macrophages at low concentrations $(1 \mu \mathrm{g} / \mathrm{mL})$. Similar patterns were observed in the accumulation of nitrites and iNOS gene expression in RAW264.7 cells treated with levan (Fig. 4(A), (C)). In addition, our results showed that DFA-IV enhanced maximal tumoricidal activity of macrophages at $100 \mu \mathrm{g} / \mathrm{mL}$, which was similar to that seen in LPS/IFN- $\gamma$-activated RAW264.7 cells that were used as a positive control (Fig. 3(B)).

Effects of levan and DFA-IV on nitric oxide production and iNOS gene expression

Since NO is related to cytotoxic function of macrophages against a variety of tumors and microorganisms and is produced in high amounts by iNOS in activated macrophages $(14,15)$, we examined the effects of levan 


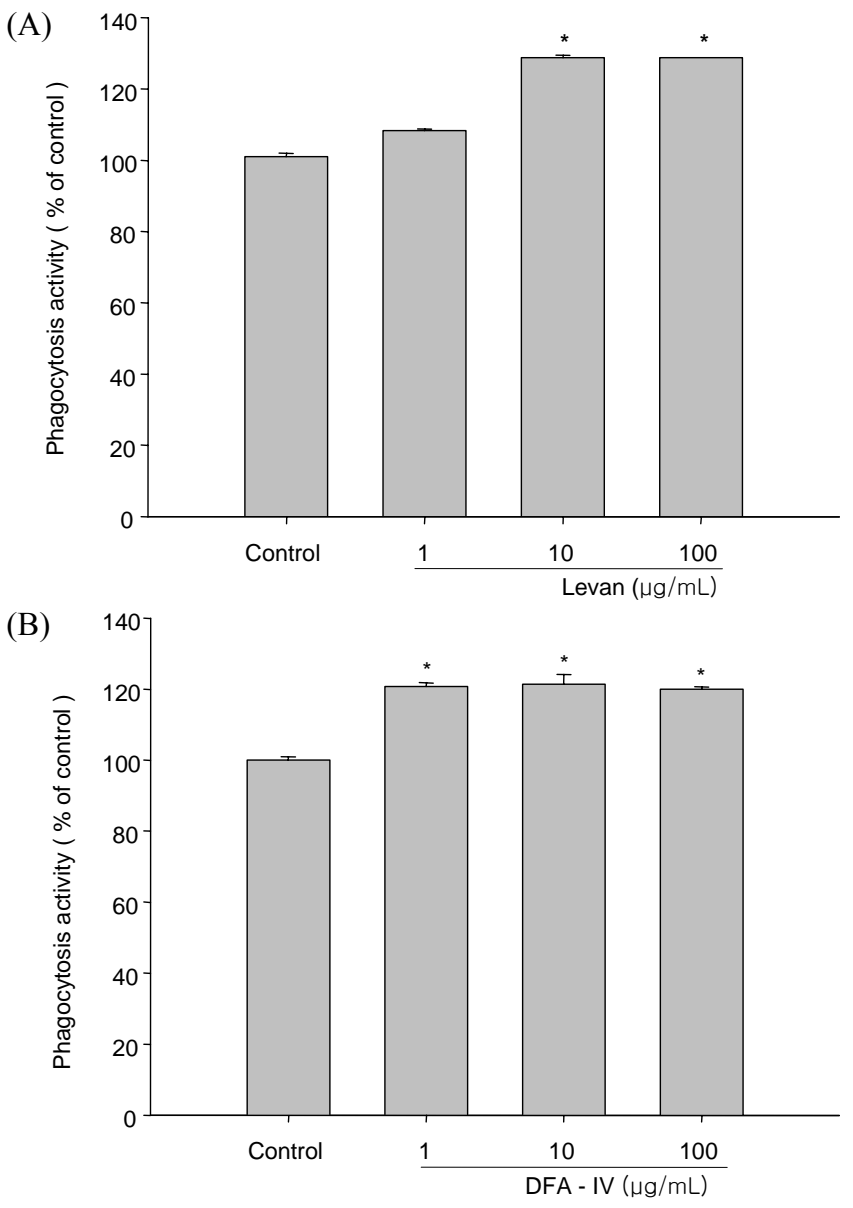

Fig. 2. Effects of levan and DFA-IV on phagocytosis of RAW264.7 cells. RAW264.7 cells were treated with levan and DFA-IV for $24 \mathrm{~h}$, respectively and then incubated with media containing zymosan $\left(1 \times 10^{6}\right.$ particles $\left./ \mathrm{mL}\right)$ and NBT $(0.6$ $\mathrm{mg} / \mathrm{mL}$ ) for $1 \mathrm{~h}$. Formazan formation was measured at 540 $\mathrm{nm}$. The data represents the mean $\pm \mathrm{SE}$ of quadruplicate experiments. ${ }^{*} \mathrm{p}<0.05$; significantly different from the control (no treatment).

and DFA-IV on both NO production and iNOS gene expression by assaying iNOS protein levels. As shown in Fig. 4, the treatment of cells with levan or DFA-IV increased the production of $\mathrm{NO}$ and $\mathrm{NOS}$ gene expression.

In the present study, our data demonstrate that levan and DFA-IV have immunomodulatory effects on tumoricidal activity and phagocytosis of macrophages. Moreover, levan and DFA-IV increased NO production and iNOS gene expression of macrophages.

Unexpectedly, levan maximally enhanced tumoricidal activity of macrophages at low concentrations $(1 \mu \mathrm{g} /$ $\mathrm{mL}$ ). Similar results were obtained for iNOS levels and NO production in levan-treated RAW264.7 cells. At the present time, we do not know why tumoricidal activity is less induced by levan at high concentrations. It is plausible that cells could be desensitized by levan at high concentrations and subsequently cause the modification
(A)

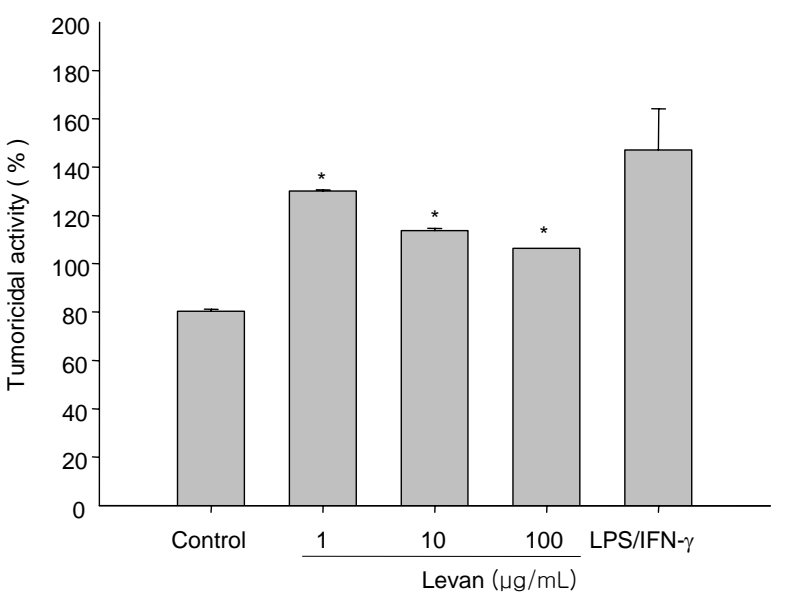

(B)

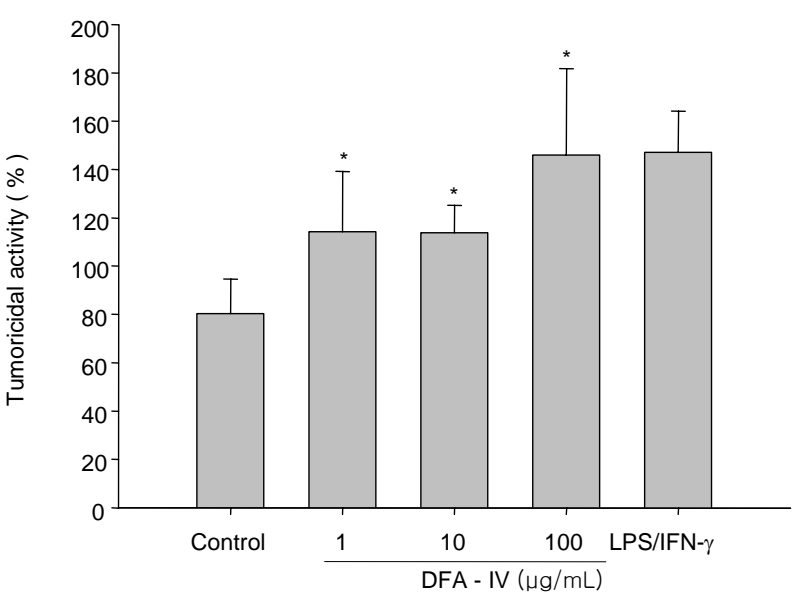

Fig. 3. Effects of levan and DFA-IV on tumoricidal activities in RAW264.7 cells. The cells were co-cultured with target cells (B16) at an effector/ target ratio of 10:1 for $24 \mathrm{~h}$ in the presence or absence of various doses of levan and DFA-IV, respectively. LPS $(1 \mu \mathrm{g} / \mathrm{mL})$ plus IFN- $\gamma(40 \mathrm{u} / \mathrm{mL})$ was used as a positive control. Macrophage tumoricidal activity was calculated as described in material and methods. The formazan formation of macrophages was determined by MTT assay. Cell density was measured at $540 \mathrm{~nm}$. The data represents the mean $\pm \mathrm{SE}$ of quadruplicate experiments. ${ }^{*} \mathrm{p}<0.05$; significantly different from the control (no treatment).

of receptor molecules. However, in our system, our results suggest that the tumoricidal activity induced by levan or DFA-IV might be mediated by the production of NO.

It has been reported that levan produced by Aerobacter levanicum $(20,21)$ and Zymomonas mobilis $(22,23)$, displayed anti-tumour and immunomodulatory effects. $\mathrm{Xu}$ et al. also suggested that levan might be related to the immunostimulatory activity of natto and levan suppressed allergic inflammation with IgE production (7). In the present study, our data suggest that NO production as well as tumoricidal and phagocytotic activities were significantly increased in both levan- and DFA-IV-treated groups. Therefore, DFA-IV has immunomodulatory effects which are similar to those of levan, suggesting 
(A)

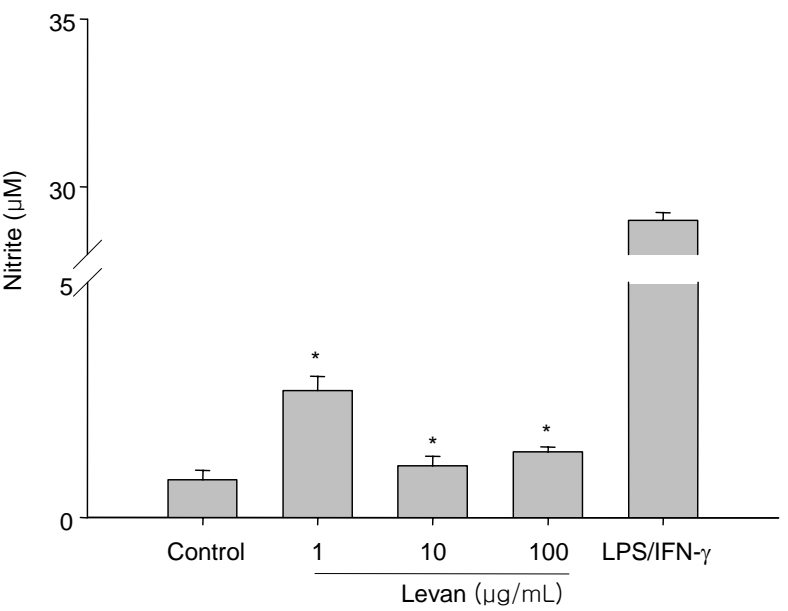

(B)

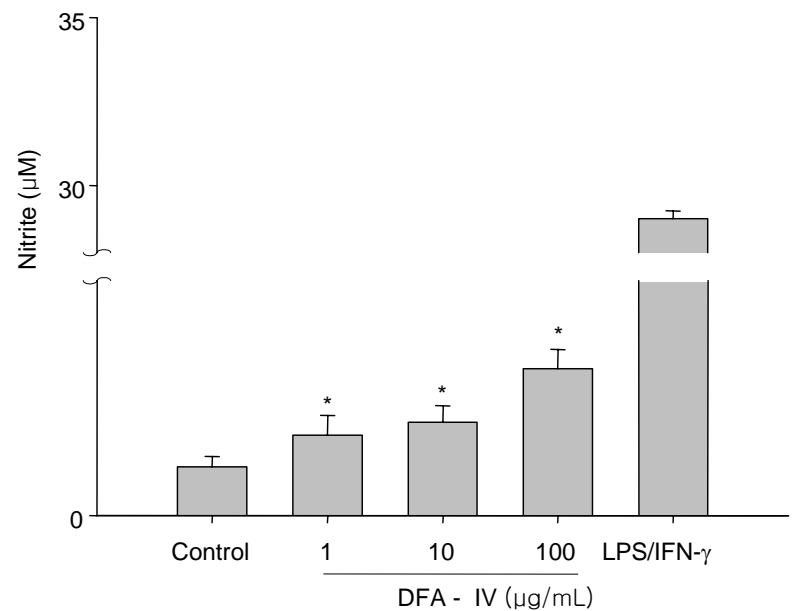

(C)

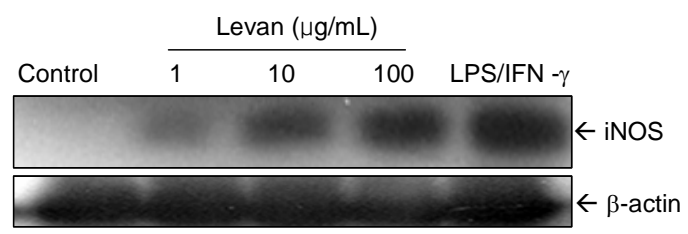

(D)

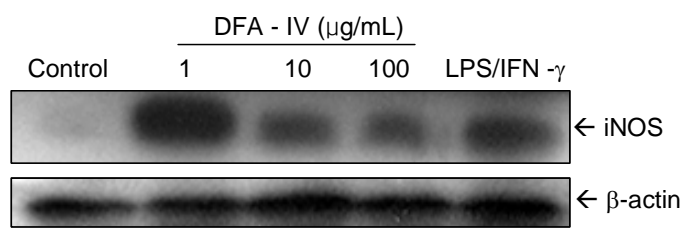

Fig. 4. The effects of in levan and DFA-IV on production of nitrite [(A), (B)] and iNOS gene expression in RAW264.7 cells $[(\mathrm{C}),(\mathrm{D})]$. RAW264.7 $\left(1 \times 10^{4}\right.$ cells/well $)$ were treated with various concentration of in levan and DFA-IV for 24 h. LPS $(1 \mu \mathrm{g} / \mathrm{mL})$ plus IFN- $\gamma(40 \mathrm{u} / \mathrm{mL})$ was used as a positive control (lane 5). Culture supernatants were collected and the levels of nitrite were measured as described in materials and method. The data represents the mean $\pm S E$ of quadruplicate experiments. ${ }^{*} \mathrm{p}<0.05$; significantly different from the control (no treatment). RAW264.7 were treated with two samples for $24 \mathrm{~h}$. Total protein was extracted and subjected to Western blot analysis for iNOS and $\beta$-actin gene.

that DFA-IV could be a substitute for levan as a functional food, and as such have immunotherapeutic useful- ness in cancer therapy.

\section{ACKNOWLEDGEMENTS}

This work was supported by grant No. RTI05-01-02 from the Regional Technology Innovation Program of the Ministry of Commerce, Industry and Energy (MOCIE).

\section{REFERENCES}

1. Han YW. 1989. Levan production by Bacillus polymyxa. $J$ Ind Microbiol 4: 447-452.

2. Saito K, Tomita F. 2000. Difructose anhydrides: their mass-production and physiological functions. Biosci Biotechnol Biochem 64: 1321-1327.

3. Han YW. 1990. Microbial levan. Adv Appl Microbiol 35: 171-194.

4. Jang KH, Ryu EJ, Park BS, Song KB, Kang SA, Kim $\mathrm{CH}$, Uhm TB, Park YI, Rhee SK. 2003. Levan fructotrasferase from Arthrobacter oxydans J17-21 catalyzes the formation of the di-D-fructose dianhydride IV from levan. J Agric Food Chem 51: 2632-2636.

5. Song KB, Bae KS, Lee YB, Lee KY, Rhee SK. 2000. Characteristics of levan fructotransferase from Arthrobacter ureafaciens K2032 and difructose anhydride IV formation from levan. Enzyme Microb Technol 27: 212-218.

6. Kim CH, Jang EK, Kim SH, Jang KH, Kang SA, Song KB, Kwon OS, Rhee SK. 2005. Molecular cloning of levan fructotransferase gene from Arthrobacter ureafaciens K2032 and its expression in Escherichia coli for the production of difructose dianhydride IV. Lett Appl Microbiol 40: 228-234.

7. Xu Q, Yajima T, Li W, Saito K, Ohshima Y, Yoshikai Y. 2006. Levan (beta-2, 6-fructan), a major fraction of fermented soybean mucilage, displays immunostimulating properties via Toll-like receptor 4 signalling: induction of interleukin-12 production and suppression of T-helper type 2 response and immunoglobulin E production. Clin Exp Allergy 36: 94-101.

8. Hahn H, Kaufmann SH. 1981. The role of cell-mediated immunity in bacterial infections. Rev Infect Dis 3: 12211250 .

9. Verstovsek S, Maccubbin D, Ehrke MJ, Mihich E. 1992. Tumoricidal activation of murine resident peritoneal macrophages by interleukin 2 and tumor necrosis factor alpha. Cancer Res 52: 3880-3885.

10. Adams DO, Hamilton TA. 1984. The cell biology of macrophage activation. Annu Rev Immunol 2: 283-318.

11. Burleson GR, Dean JH, Munson AE. 1995. Introduction to the mononuclear phagocyte system. In Methods in immunotoxicology. Wiley-Liss, New York, USA. Vol 2, p $3-13$.

12. Nathan CF. 1987. Secretory products of macrophages. $J$ Clin Invest 79: 319-326.

13. Fidler IJ, Kleinerman ES. 1983. Therapy of cancer metastasis by systemic activation of macrophages: from the bench to the clinic. Res Immunol 144: 284-287.

14. Keller R, Keist R. 1989. Abilities of activated macrophages to manifest tumoricidal activity and to generate reactive nitrogen intermediates: a comparative study in vitro and ex vivo. Biochem Biophys Res Commun 164: 968-973.

15. Bredt DS, Snyder SH. 1994. Nitric oxide: a physiologic 
messenger molecule. Annu Rev Biochem 63: 175-195.

16. Jang $\mathrm{KH}$, Song KB, Kim $\mathrm{CH}$, Chung BH, Kang SA, Chun UH, Choue RW, Rhee SK. 2001. Comparison of characteristics of levan produced by different preparations of levansucrase from Zymomonas mobilis. Biotechnol Lett 23: 339-344.

17. Mosmann T. 1983. Rapid colorimetric assay for cellular growth and survival: application to proliferation and cytotoxicity assay. J Immunol Methods 65: 55-63.

18. Okimura T, Ogawa M, Yamauchi T. 1986. Stress and immune responses. III. Effect of resistant stress on delayed type hypersensitivity (DTH) response, natural killer (NK) activity and phagocytosis in mice. Jpn J Pharmacol 41: 229-235.

19. Ding AH, Nathan CF, Stuer DJ. 1988. Release of reactive nitrogen intermediates and reactive oxygen intermediates from mouse peritoneal macrophages. Comparison of acti- vating cytokines and evidence for independent production. J Immunol 141: 2407-2412.

20. Leibovici J, Susskind-Brudner G, Wolman M. 1980. Direct antitumor effect of high-molecular-weight levan on Lewis lung carcinoma cells in mice. J Natl Cancer Inst 65: 391396.

21. Stark Y, Leibovici J. 1986. Different effects of the polysaccharide levan on the oncogenicity of cells of two variants of Lewis lung carcinoma. Br J Exp Pathol 67: 141147.

22. Calazans GMT, Lima RC, de Franca FP, Lopes CE. 2000. Molecular weight and antitumour activity of Zymomonas mobilis levans. Int J Biol Macromol 27: 245-247.

23. Yoo SH, Yoon EJ, Cha J, Lee HG. 2004. Antitumor activity of levan polysaccharides from selected microorganisms. Int J Biol Macromol 34: 37-41.

(Received February 19, 2008; Accepted March 12, 2008) 